Presented at the 12th Topical Conference on Radic Frequercy Fower in Plasmas,

Savannah, GA, Apri1 1-3, 1997.

\title{
CONF-9784102--
}

\section{High-Harmonic Fast Wave Heating Experiments in CDX-U ${ }^{1}$}

\author{
J. Menard, R. Majeski, M. Ono, J. R. Wilson, T. Munsat, and \\ T. Seki ${ }^{\dagger}$
}

Princeton Plasma Physics Laboratory, Princeton, NJ 08543-0451

${ }^{\dagger}$ Nationat Institute of Fusion Science, Japan

\begin{abstract}
One of the primary objectives of the proposed National Spherical Tokamak Experiment (NSTX) [1] is the investigation of very high $\beta$ regimes. Consequently, finding efficient methods of non-inductive heating and current drive required to heat and sustain such plasmas is of considerable importance. High frequency fast waves are a promising candidate in this regard. However, in NSTX, the field-line pitch at the outer midplane will range from 0 to up to 60 degrees from plasma start-up to current flat-top. Thus, antenna strap orientation with respect to the edge magnetic field may have a serious impact on power coupling and absorption. To address this issue, the vacuum vessel of the Current Drive Experiment - Upgrade (CDX-U) spherical tokamak has been upgraded to accommodate a rotatable two-strap antenna capable of handling several hundred kilowatts in short pulses. Details of the antenna design and results from loading measurements made as a function of power, strap angle, and strap phasing will be presented. Results from microwave scattering experiments will also be discussed.
\end{abstract}

\section{INTRODUCTION}

Because of its tight geometry, the spherical tokamak has very limited ohmic heating capability. Consequently, the development of non-inductive heating and current drive methods useful for plasma start-up and sustainment is of considerable importance. In contrast to lower hybrid and electron cyclotron waves, which have severe accessibility problems in high $\beta$ plasmas, fast waves in the intermediate frequency regime with $\omega \approx 20 \Omega_{c i}$ experience sufficient damping on electrons to consider localized power deposition $[2,3]$. However, the field-line pitch at the outer midplane is predicted to vary from 0 degrees at plasma start-up to up to 60 degrees during the sustainment phase of very high $\beta$ advanced tokamak discharges. Thus, antenna strap orientation with respect to the edge magnetic field could impact the power deposition and current drive profiles of the fast wave and the coupling characteristics of the antenna. To

1) This work was supported by the United States Department of Energy under Contract No. DE-AC02-760-CH0-3073. 


\section{DISCLAIMER}

This report was prepared as an account of work sponsored by an agency of the United States Government. Neither the United States Government nor any agency thereof, nor any of their employees, make any warranty, express or implied, or assumes any legal liability or responsibility for the accuracy, completeness, or usefulness of any information, apparatus, product, or process disclosed, or represents that its use would not infringe privately owned rights. Reference herein to any specific commercial product, process, or service by trade name, trademark, manufacturer, or otherwise does not necessarily constitute or imply its endorsement, recommendation, or favoring by the United States Government or any agency thereof. The views and opinions of authors expressed herein do not necessarily state or reflect those of the United States Government or any agency thereof. 


\section{DISCLAIMER}

Portions of this document may be illegible in electronic image products. Images are produced from the best available original document. 
address these issues in more detail, the aluminum outer cylindrical section of the CDX-U vacuum chamber was replaced with a larger diameter stainless steel version to accomodate a fast wave antenna on the outer midplane without decreasing the plasma size. Details of the antenna design, results from microwave scattering experiments, and loading measurements made as a function of power, strap angle, and strap phasing are discussed below. For all data that follows, hydrogen plasmas were used and the RF frequency was $12 \mathrm{MHz}$, corresponding to $\omega_{\mathrm{RF}} / \Omega_{\mathrm{ci}}=10-12$ at the antenna.

\section{ANTENNA DESIGN}

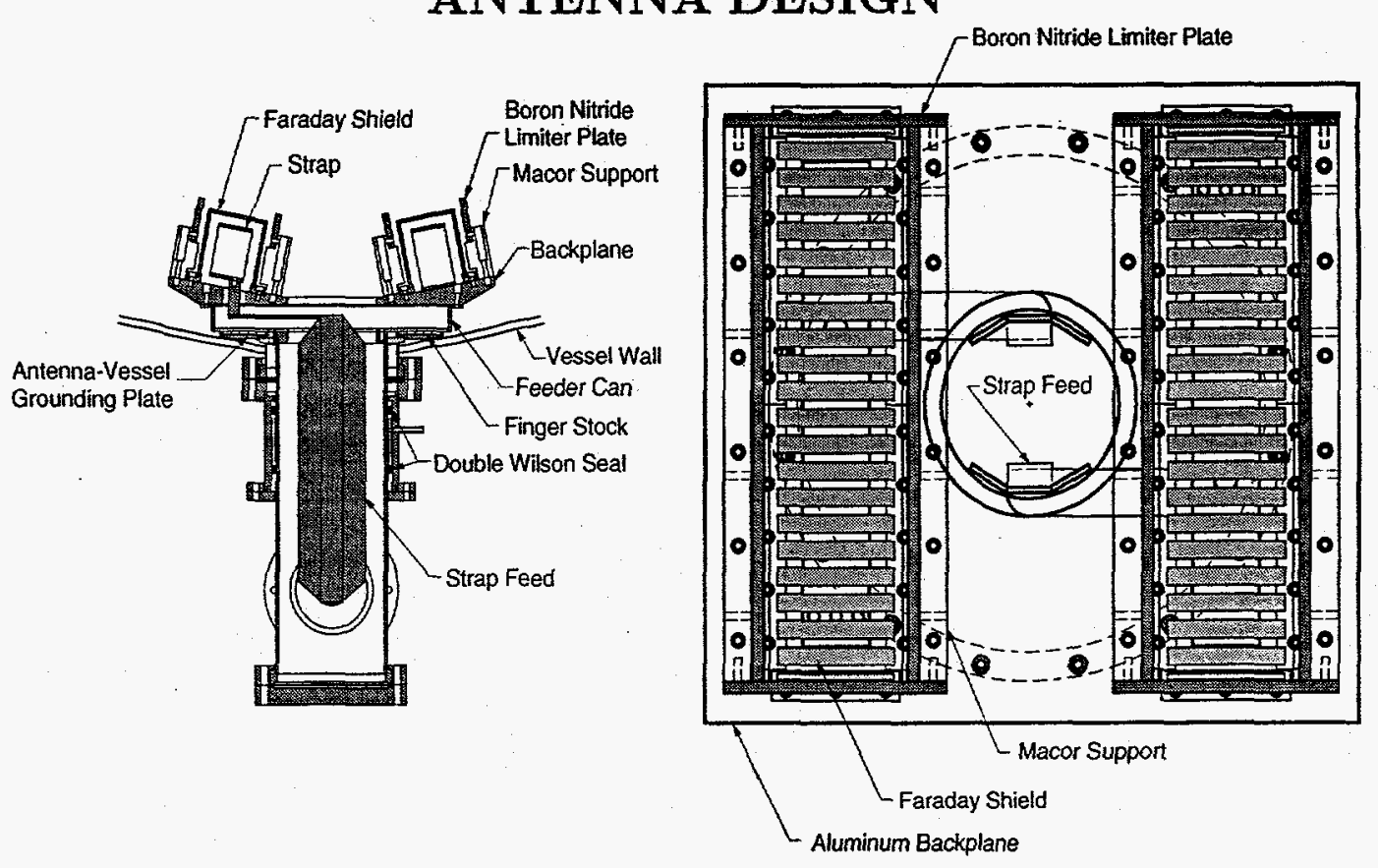

FIGURE 1. Top and front views of the CDX-U high-harmonic fast wave antenna.

The CDX-U high-harmonic fast wave antenna is a two-strap antenna capable of handling several hundred kilowatts in short pulses $(<10 \mathrm{msec})$. The strap height, width, and center-to-center separation are approximately $27 \mathrm{~cm}$, $3.8 \mathrm{~cm}$, and $22 \mathrm{~cm}$, respectively. The strap separation was chosen to launch toroidal mode number $n_{\phi} \approx 8$ with $0-\pi$ phasing. Each strap is surrounded by 4 plates of 0.25 inch thick hot-pressed binder-free boron nitride to withstand edge heat flux and minimize RF induced sheath effects. The straps are bent from 0.125 inch thick copper sheet and are mounted on an aluminum backplane. The backplane is beveled and the limiter plates are cut so as to conform to the plasma shape at the outer midplane independent of antenna rotation angle. The straps are mounted anti-phase on the backplane but are fed in phase. Thus, by properly choosing the feed shape and proximity to the ground plane, the strap to strap mutual inductance has been nearly eliminated, allowing arbitrary strap phasing with no changes in the external matching circuitry. The primary novelty of the CDX-U fast wave antenna is that it can 
be manually rotated to arbitrary angle between discharges. Grounding of the antenna to the vacuum chamber is achieved by compressing radially mounted bi-directional finger stock between a grounding plate attached to the vessel and the feeder can of the antenna. Top and front views of the antenna are shown in Figure 1.

\section{HIGH POWER LOADING DATA}

The first indication that power is being coupled to the fast wave is that the plasma loading resistance becomes independent of power as the power is raised above a few kilowatts. As shown in Figure 2a, this trend exists for both $0-\pi$ and $0-\pi / 2$ phasings. The higher loading for $0-\pi / 2$ phasing is expected, due to the shorter cut-off distance for this lower $k_{\|}$launch. As shown in Figure $2 \mathrm{~b}$, the plasma loading decreases as the straps become increasingly parallel to B. In agreement with experiment, the 1-D slab ICRF code ANTBER [4] also predicts higher loading for $0-\pi / 2$ and decreased loading as $\theta_{\text {STRAP }} \rightarrow 90^{\circ}$, though the value predicted is somewhat sensitive to the density profile assumed between the strap limiters and Faraday shields.
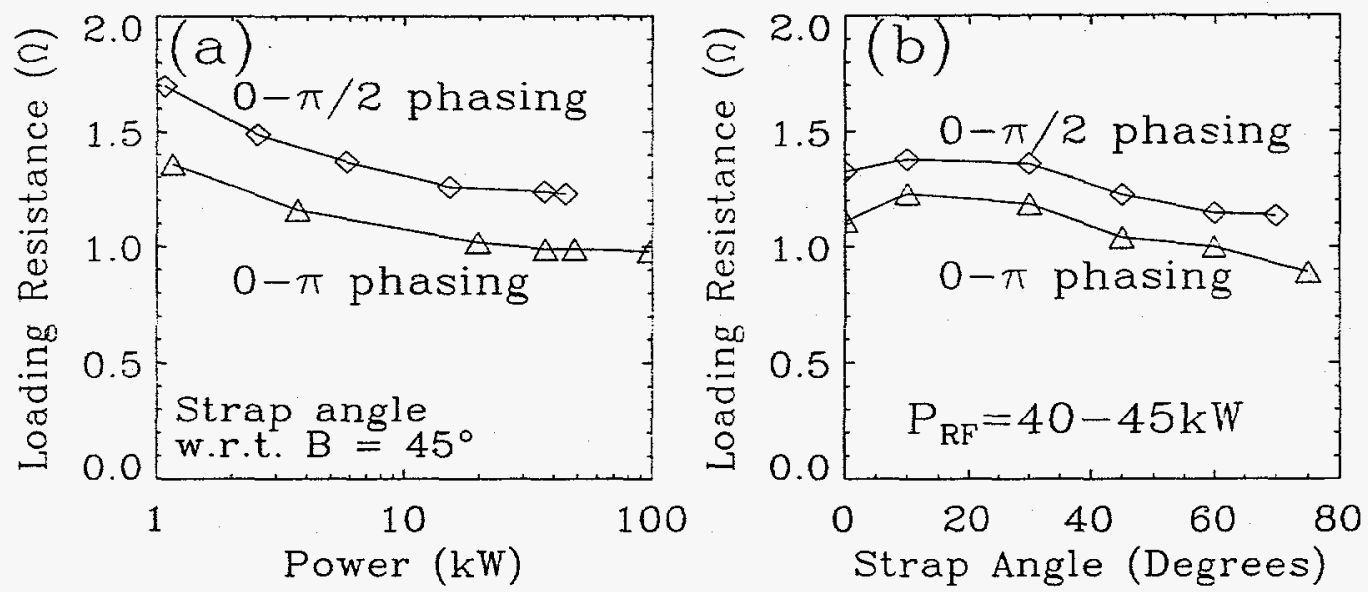

FIGURE 2. (a) Plasma loading versus power and (b) loading versus strap angle for $0-\pi$ and $0-\pi / 2$ phasings. Note that the local field-line pitch of $30-35^{\circ}$ has been subtracted out, so straps are parallel to $B$ when the strap angle $=90^{\circ}$.

\section{MICROWAVE SCATTERING DATA}

By using the vertical beam of the CDX-U $2 \mathrm{~mm}$ microwave interferometer [5] to measure RF induced density fluctuations $\left(90^{\circ}\right.$ away from the antenna. toroidally) we have confirmed that wave fields are present throughout the plasma cross-section. As shown in Figure 3a, the scattered signal amplitude is proportional to $\int n_{\mathrm{e}} \mathrm{dz}$ and decreases as the microware beam major radius is increased from the plasma center radius of $35 \mathrm{~cm}$ (top curve) to $R=45 \mathrm{~cm}$ (bottom curve). Note that $\mathrm{R}=45 \mathrm{~cm}$ corresponds to $\mathrm{r} / \mathrm{a} \approx \frac{1}{2}$ at the midplane. 
As shown in Figure $3 \mathrm{~b}$, when the straps are nearly orthogonal to B the normalized signal is strongest in the plasma core, possibly due to wave focusing effects. More interestingly, as the straps become parallel to B, the normalized signal in the core drops relative to the signal further out, possibly due to the excitation of surface modes. This result will be explored in more detail in the near future with edge B-dot probes on loan from the Pegasus group at the University of Wisconsin.
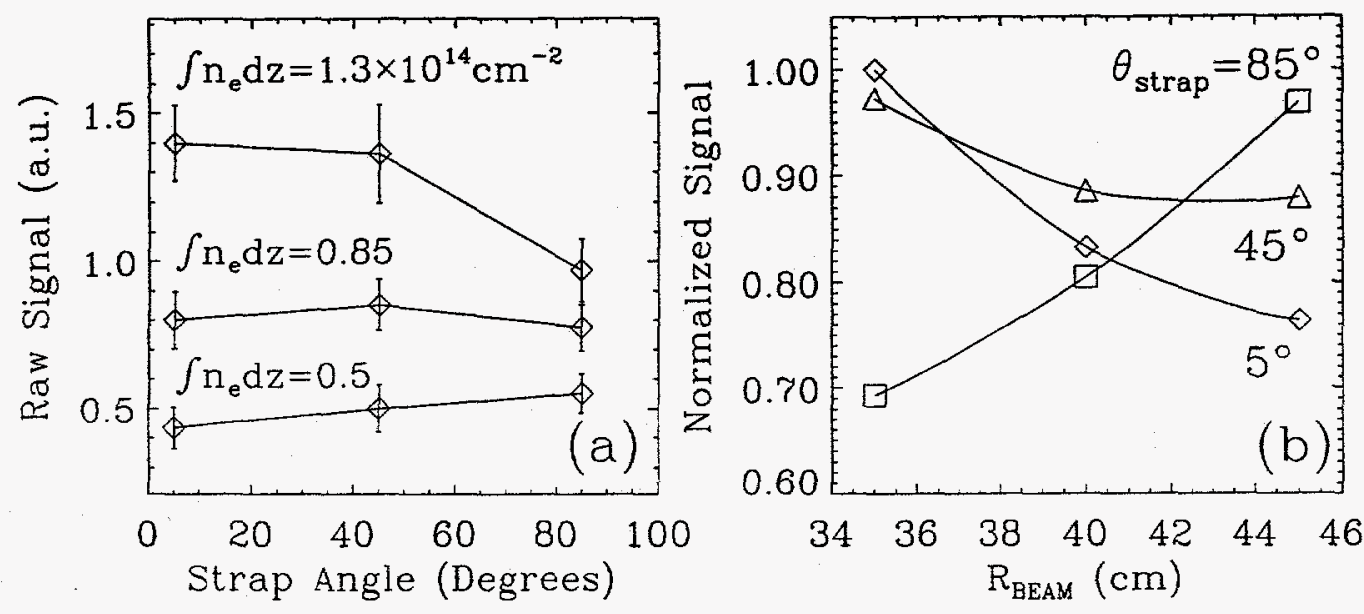

FIGURE 3. (a) Scattered microwave signal due to RF induced density fluctuations as a function of strap angle and line integrated density (major radius). Straps are parallel to B when the strap angle $=90^{\circ}$. (b) Scattering signal with $\int n_{e} d z$ dependence scaled out.

\section{CONCLUSIONS}

A rotatable two-strap antenna has been installed in CDX-U to investigate the loading and wave physics of high frequency fast wares as a function of the angle between the antenna straps and the edge magnetic field. Plasma loading decreases as the straps become non-orthogonal to $B$, in reasonable agreeement with theoretical predictions for both $0-\pi$ and $0-\pi / 2$ phasings. Microwave scattering experiments confirm that $\mathrm{RF}$ wave fields exist throughout the plasma cross-section and suggest that the strap orientation could impact the wave field profiles. Recent vacuum conditioning upgrades (Ti-gettering between shots and antenna limiter baking) have nearly eliminated $R F$ induced fueling effects and should greatly aid attempts to measure direct electron heating with Thomson scattering in the near term.

\section{REFERENCES}

1. J. Spitzer et al. Fusion Technology 30, 1337 (1996).

2. M. Ono, Phys. Plasmas 2, 4075 (1995).

3. J. Menard, R. Majeski, M. Ono, and J. Wilson, Proc. $11^{\text {th }}$ topical conf. on RF power in plasmas, 59 (1995).

4. M. Brambilla, Nucl. Fus. 28, 549 (1988).

5. C. Forest, G. Greene, and M. Ono, Rev. Sci. Instrum. 61, 2888 (1990). 